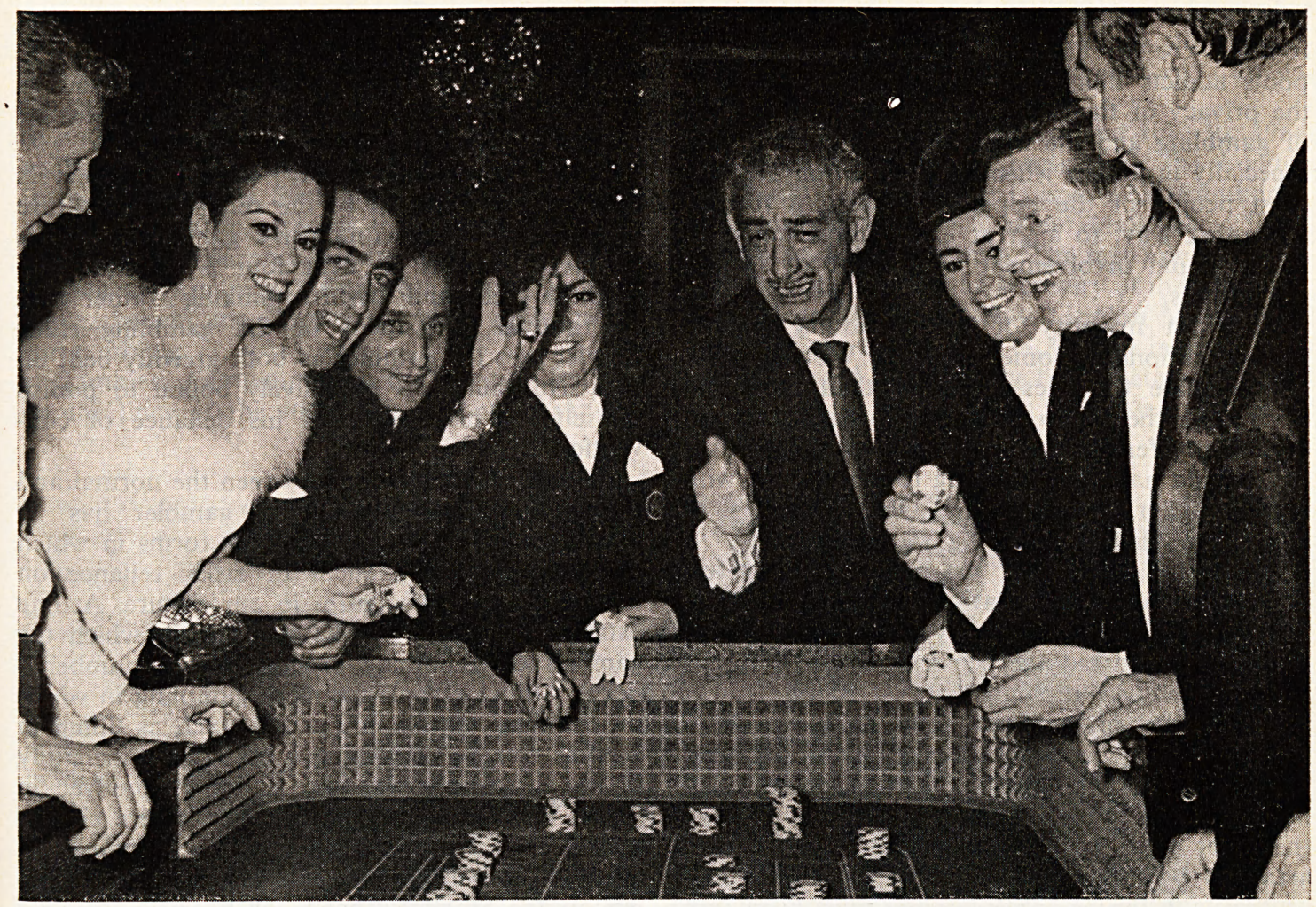

An American 'tourist/gambler' tries hls first London table.

Photo: Syndication International

\title{
THE GAMBLERS
}

An assessment of the scale of the problem of excessive gambling by Dr. F. R. C. Casson, Hon. psychiatrist to Gamblers Anonymous and author of 'The compulsive gambler' which is due to be published by Allen and Unwin in the new year.

IN BRITAIN, since the passage of the 1960 Betting and Gaming Act, gambling has rightly been termed a growth industry. In the last annual report of the Churches' Council on Gambling, gambling's annual turnover was estimated as some $£ 2,230$ million. One leading expert places Britain foremost among European nations for its per capita gambling expenditure, and fourth in the world league, only excelled by Australia, the U.S.A. and New Zealand.

There is a long tradition in England of interest in games of chance and in gambling on sports such as horse-racing, boxing, cock-fighting and whippet-racing. Geoffrey Gorer has drawn attention to the British pride in being better sportsmen and better 'sports' than most foreigners. He sees this rustic attitude to sportsmanship and sporting events as a basic ingredient in British gambling.

To the extent that the turnover on gambling on horse-racing, dog-racing and football pools still accounts for the major part of Britain's gambling bill, Gorer's view is tenable. However, the nation now boasts some 16,000 betting shops, 2,000 bingo clubs, 1,000 gaming clubs and thousands of gaming and amusement machines to cater for its gambling appetites.

The increase in Britain's population since the eighteenth century and the urbanisation of a nation still nostalgic for the countryside have brought about more mechanised and impersonal forms of gambling. Few punters go to a racecourse to place their bets, compared to the thous- 
ands who frequent the betting shops. Even the football crowds are vastly outnumbered by the pools addicts filling in their weekly coupons in the privacy of their own sitting-rooms. The thrill of gambling and the hope of making a big win, especially in an era when heavy taxation deprives most people of the hopes of making a fortune any other way, to a great extent must outweigh the personal involvement with sport of former generations.

The vast majority of British adults gamble, some occasionally, some regularly. Women probably gamble to a lesser extent than men, but since 1961 the Bingo halls have attracted a predominantly female clientele and many housewives who would have felt it wrong to place a bet with a bookmaker's 'runner' now think nothing of patronising the local betting shop.

Like other habits, for the majority of its followers, gambling is a relatively harmless pastime. True, a young workman may lose money he can ill afford, or an old age pensioner spend some of her scanty housekeeping money at Bingo.

A minority of gamblers seem unable to limit their gambling, to stop when they have lost what they can afford to lose-or to stop when they have had what would seem a satisfactory win. In the latter case, as the odds in any gambling are arranged by the gambling promoter to keep him profitably in business, the gambler must inevitably lose if he continues risking his money.

This uncontrolled type of gambler is often termed a 'compulsive' or pathological gambler. An analogy can be drawn with the drinker who, unlike the majority of social drinkers, has lost control of his drinking habit and becomes known as an alcoholic.

Just as with the drinker, the extent or regularity of a man's indulgence in his habit do not by themselves make him compulsive. There seems to be a difference in quality, rather than in quantity, between the gambling of a social gambler and his compulsive fellow-gambler. Very often, as with the regular drinker who, at some point in his drinking career, can be said to have become an alcoholic, the regular gambler may change into a compulsive gambler.

The American psychoanalyst, Edmund Bergler, has made an extensive study of gamblers, and considers that everyone in our western culture is a potential gambler, either of the normal or the pathological variety. He gives six characteristics of the latter: gambling is a chronic and repetitive experience in his life; gambling becomes his allconsuming interest; he is pathologically optimistic about winning, never learning a lesson from his losses; he cannot stop when winning; despite initial caution, he eventually risks more than he can afford to lose; he seeks and enjoys a mysterious thrill, part pain, part pleasure.

Bergler explains the gambling compulsion as being a residue of the fantasies of omnipotence normal in young children.

Other psychoanalytically - oriented observers have drawn attention to the relatively immature personality of the compulsive gambler, and the manner in which his behaviour is motivated by infantile greed and 'wishful thinking', rather than by rational assessment of the gambling risks. Bergler sees the gambler as both greedily bent on excessive gains and obsessively bound to punish himself for his greed and his defiance of convention.

Perhaps the distinction between the normal and the pathological (compulsive) gambler has an illustrative parallel in the various forms in which gambling-taking chances or risks, reliance on luck and so forth-figures in our culture. At one extreme are activities like lotteries, in which the gambler does nothing except draw a numbered ticket. Midway, some forms of gambling in which the gambler takes some action, such as filling in a pools coupon or placing a bet after some study of racing 'form'; still more action is involved in games of skill or athletic contests, where chance is still a sizeable ingredient in the outcome. At the other extreme, some enterprises such as dealing on the Stock Exchange or business ventures in general, where chance factors are minimised by close attention to the condition of the market, spreading risks by means of insurance, and so on.

Lotteries originally were supposed to show the disposition of the gods to confer favours on some lucky mortals and withhold them from their luckless rivals. This primitive mode of thinking is still operative in modern man and it obtains expression in the belief of most compulsive gamblers that nothing they themselves can do will achieve results comparable to 'having luck on my side'.

Paul C., a young company executive in Los Angeles, was squandering so much of his $\$ 15,000$ salary that his family were without food one evening when he left them to drive down to the poker tables of Gardena. He told me, years later, that he remembers distinctly how convinced he was that he was going to win enough that night to solve all his financial difficulties and put a stop to his wife's reproaches. Naturally, he again lost every cent.

The compulsive gambler is, to most peopleeven to other gamblers-a baffling, incomprehensible character. It is easy to sneer at him for being weak-willed, greedy for easy money, for wanting to make a big killing and win popularity by having money to lavish on his cronies. To some extent people are becoming aware that the man 
who drinks compulsively is suffering from an illness and is not just a vicious drunkard. In the same way, with the increase of gambling among our population, the public needs to be educated to understand that some gamblers become unable to limit what, for the majority of us, is a harmless form of relaxation. Such gamblers sooner or later get themselves into trouble through debt, borrowing from friends and family, banks and moneylenders and, in many instances, turning to theft, embezzlement and forgery to obtain more money for gambling.

Gamblers Anonymous, an organisation founded on the lines of the successful Alcoholics Anony- mous, was started in Los Angeles in September 1957. It now has well over a hundred groups operating in the major cities of the U.S.A., Canada, Great Britain and Australia.

A branch opened in London on July 10, 1964, and there are now six meetings in the London area and other groups in Glasgow (2), Edinburgh, Newcastle-upon-Tyne, Sheffield, Manchester, Birmingham and Bournemouth. The first London meeting was organised by the secretary of the Churches' Council on Gambling (Rev. Gordon Moody) and an American member of G.A. then in England. I was privileged to attend the first meeting on behalf of The Lancet. As I wrote in my subsequent report,

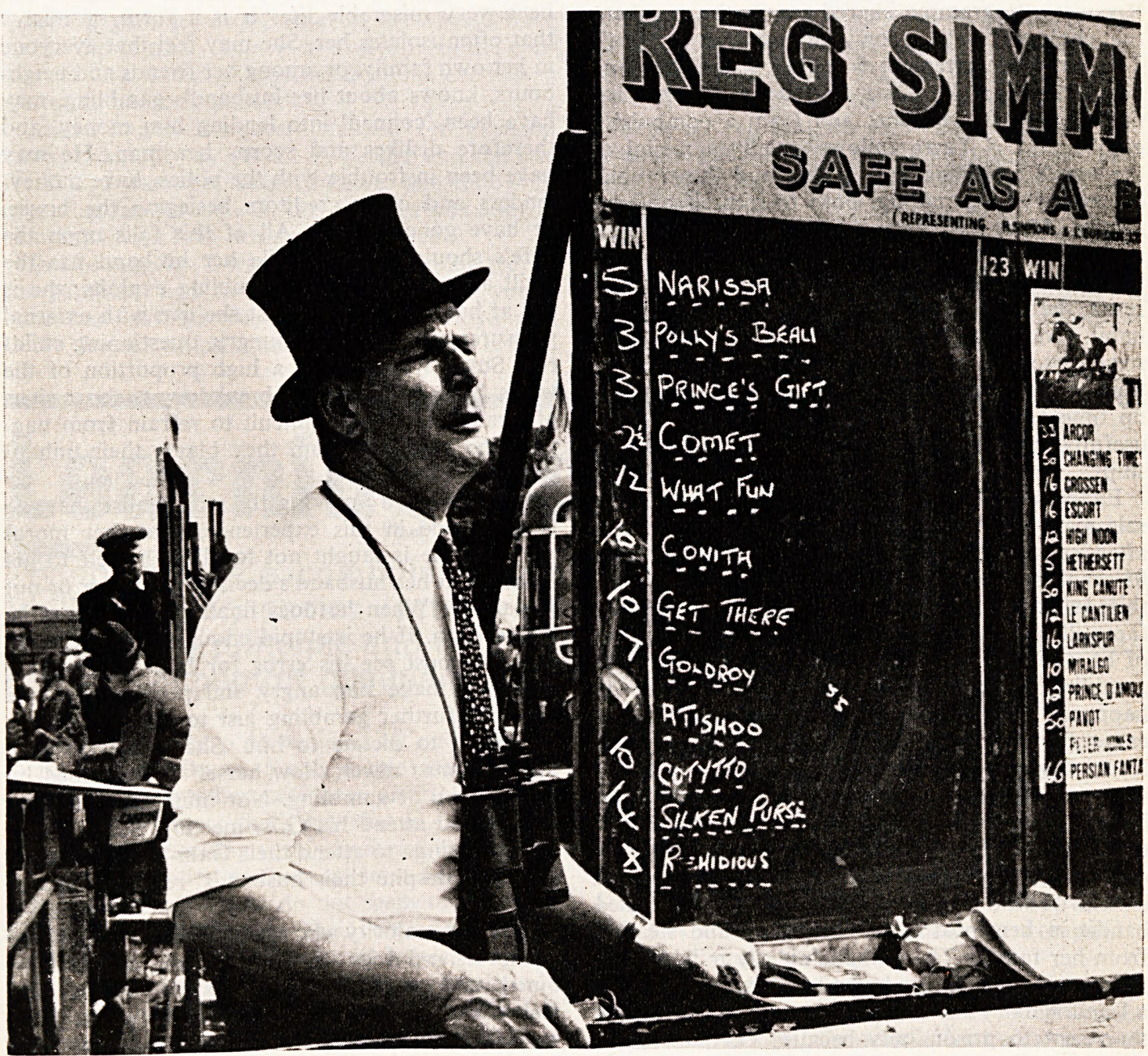

The flamboyant, independent 'on-course' bookmaker is probably the most traditional figure in the world of gambling but now he only handles a comparatively small proportion of the huge $£ 2,230$ million annual gambling turnover in Britain. Photo: Syndication International 
'The pattern of the stories was almost monotonous, but the depth of feeling with which men revealed their tragic experiences gave each recital a unique pathos. By the end of the evening there was a group in the room, not just a collection of embarrassed strangers.'

It is this group dynamic by which G.A. exerts its powerful effect upon the compulsive gambler who sincerely wants to get free from his addiction. He finds himself, for the first time, in a group of people who have had similar experiences, who can fully understand whatever he has to relate, and who will not condemn him nor be deceived by his lies and rationalisations.

One of the members takes the chair at the meeting. After a preliminary reading aloud of the G.'A. Recovery Programme, shared among the members, the chairman calls upon one member to speak. The personal statement is called a 'therapy' and begins in a set formula, the man giving his first name only: 'I am John, and I am a compulsive gambler. ... There follows usually a recital of the man's gambling experiences and the troubles caused by his gambling, both to himself and his family. Men who have attended for some time may have to admit that they have slipped, all have to struggle to greater or lesser degree to resist the temptation to revert to an engrained habit. Gradually, the stories are more of the slow, steady progress of personal and family rehabilitation, realisation of how much gambling has used up time and energies that might have been more usefully spent in achieving richer family relationships.

Examples crowd to mind: the charming Irish salesman who told how his first marriage ended, after years of gambling, with his despairing wife first making a suicidal attempt and then, when even this failed to stop him gambling, bidding him farewell and taking their small son with her, out of his life, and how that same day he again went gambling. The middle-aged business executive who happened to visit a casino on a business trip, became fascinated by roulette and, in one year's frenzied gambling, lost the savings of a lifetime. The busy general practitioner who managed to borrow even from his patients, frequented casinos, dog-tracks and betting shops, evading his wife's questions with pleas of emergency calls. The Scots housewife who became an addict of the one-armed bandit in her local club, borrowing and stealing from her family. The pathetic elderly milkman, at the very first meeting, who had embezzled $£ 70$ from a London dairy and was placed on probation rather than sent to prison only because G.A. members went into court to plead for him.

Listening to the therapies, as I have been able to do over the year, sometimes it is difficult to feel that the gambling behaviour described is that of a person who is supposedly sane. Compulsive gambling is, indeed, a localised form of insanity, for it is based upon a firmly-held delusion that the individual is bound-this time-to win the jackpot. As in the case of my Los Angeles friend, Paul, the arguments and entreaties of friends or family to end such ruinous conduct are shrugged off or met with sullen obstinacy.

Naturally, the gambler's behaviour affects his family-the majority are married men with families. The parallel organisation for the wives and girl-friends is called Gam-Anon and it plays an important role in the recovery of the gambler, besides being of great help to many a harassed wife. To be the wife of a compulsive gambler can be a very miserable life. It is a form of misery that often isolates her. She may feel that everyone in her own family, or among her friends and neighbours, knows about her husband's gambling, may have been 'conned' into lending him money, and therefore dislikes and scorns her man. He may have been in trouble with the police, have moneylenders and other creditors besieging the house, or have gone to gaol. All of this falls upon the wife's shoulders and, while her husband has the thrill and variety of his gambling exploits, she is left at home to cope as best she can with external pressures and unhappy, hungry, questioning children. Small wonder that a high proportion of the wives have had nervous breakdowns, show signs of strain and find it difficult to refrain from nagging the men on whom they blame their unhappiness.

Gam-Anon, by making the wife realise that she is not alone in this experience, gives her moral support. She is taught not to allow herself to get involved in her husband's decisions whether or not to gamble. When he does finally stop it must be his decision. If he is stupid enough to have a slip, well, he must see his error for himself. Nagging will only make him angry and perhaps provoke him into further gambling just to get back at her for trying to dictate to him. She is taught, also, that she must never allow herself to be bribed by money won at gambling. Nor must she bribe her husband to attend his G.A. meeting. Some of the wives continue to attend their Gam-Anon meetings regularly despite their husbands' refusal to go to G.A.

The vast majority who attend G.A. have gambled on horses and dogs. This may or may not be combined with card-playing or gaming at casinos. Relatively few have become addicted to slotmachines or Bingo. In Britain, there have only been a handful of women members of G.A., but in California, owing to the popularity of poker clubs among the ladies, there are quite a few 
women members. Generally, in Britain, women face more social disapproval if they gamble heavily, which probably explains their scanty representation in G.A.

The problem of formal psychiatric treatment of the compulsive gambler is complicated by his reluctance, when he is winning, to spare time or money for treatment. When he is flat broke, he may begin treatment, but is likely to discontinue it when he thinks he has hit a winning streak. Listening to the experiences G.A. members have had with psychiatrists, it is only fair to admit that most psychiatrists are easy game for their proficiency in 'conning' and deceiving authority. Social workers, probation officers and ministers of religion fare no better in their well-meant attempts to convince the gambler of the error of his ways. I have found him a tricky person to deal with in the context of individual psychotherapy and even in a group of neurotic patients.

Initial impact has been claimed for aversion therapy, notably by Dr. C. P. Seager and the late Dr. J. C. Barker. Dr. Seager believes that follow-up rehabilitation through G.A. is an essential factor in bringing about long-lasting improvement.

In Los Angeles, I was impressed by joint groups for gamblers and their wives run by two young American psychiatrists (Drs. W. H. Boyd and D. W. Bolen) which I was able to observe briefly.
This seemed to go more deeply into the interpersonal problems underlying the compulsive gambler's maladjusted social behaviour.

From a practical point of view, Gamblers Anonymous is the most effective method of treatment available to the vast majority of compulsive gamblers. It should be recommended also as a follow-up from aversion therapy or from hospital psychiatric treatment. In America and Britain, there are G.A. groups in some of the prisons and men who have come into contact with G.A. in this way should be encouraged to attend their nearest group when they leave prison.

The Churches' Council on Gambling is still sponsoring G.A., though G.A. is financially selfsupporting, one of its tenets being that it should accept contributions only from its members. The Churches' Council, however, is doing valuable promotion work by running occasional conferences for doctors, social workers, prison and probation officers, etc., so that the existence of G.A. should be made known more widely among people concerned with helping the compulsive gambler and his family.

It should be emphasised that G.A. is non-sectarian although, as in A.A., it is suggested that the help of a 'higher power' may be necessary to overcome a habit which has become uncontrollable by its victim.

\section{Learning not to bet}

\section{Trying to cure a compulsive gambler can be extremely difficult. Dr. Philip Seager, senior lecturer in psychiatry at Sheffield University, explains the principle and methods of aversion therapy which he uses in the treatment of gamblers who want to stop.}

MAN HAS always been prepared to bet on his ability to forecast the future. Some people are eternally optimistic while others are pessimistic. The optimists may bet more than they should but usually they keep their betting within limits of their purse; a heavy loss will stop them, at least for the time being. Some individuals do not seem to have this ability to recognise that their optimism is not justified and, in spite of repeated losses, they are convinced that success is round the corner if only they keep on long enough. As a result they bet all their own money and then money which has been put aside for commitments such as electricity, fuel, food and hire purchase payments.

Eventually they borrow and sometimes steal in order to have a further bet which they are convinced will be successful and get them out of all their problems. Such optimism in the face of reality is obviously abnormal and it is now recognised that these individuals need expert treatment. The causes of their behaviour have been dealt with in the previous article. This section discusses one form of treatment for compulsive or pathological gambling.

The term 'behaviour therapy' refers to a number of different forms of treatment based on the view that much human behaviour is learned as a result of activity which has been rewarded. If, following a particular pattern of behaviour, some satisfactory result occurs for the individual then he is likely 